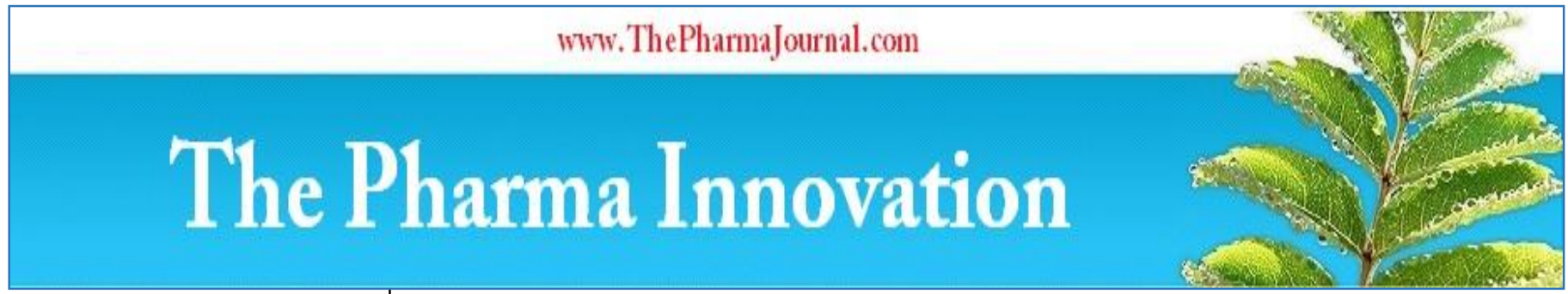

ISSN (E): 2277 - 7695

ISSN (P): 2349-8242

NAAS Rating: 5.23

TPI 2021; 10(3): 857-859

(C) $2021 \mathrm{TPI}$

www.thepharmajournal.com

Received: 14-12-2020

Accepted: 29-01-2021

\section{Neelima Netam}

Department of Floriculture and Landscape Architecture,

Pt. KLS College of Horticulture and Research Station

Rajnandgaon, IGKV,

Chhattisgarh, India

\section{Corresponding Author:} Neelima Netam

Department of Floriculture and Landscape Architecture,

Pt. KLS College of Horticulture and Research Station

Rajnandgaon, IGKV,

Chhattisgarh, India

\title{
Edible flower cultivation: A new approach in floriculture industry
}

\section{Neelima Netam}

DOI: $\underline{\text { https://doi.org/10.22271/tpi.2021.v10.i31.5896 }}$

Abstract

Flowers have held and eminent place in human's life socially, economically and aesthetically. Globally edible flower gained popularity as it add nutritional, medicinal as well as aesthetics appearance to our plate. Flowers can be used Inadding aroma, flavor and color, also decorating and preparing food and drinks. However, the chemical composition of flowers must be known before human consumption. Traditionally we used rose, marigold, hibiscus, calendula etc. in different cuisine. Flower cultivation for edible purpose strengthens the floriculture industry. This review was written to increases awareness on edible flower in floriculture sector.

Keywords: Flowers, edible, nutritional, medicinal, aesthetics, cuisine, floriculture industry

\section{Introduction}

Floriculture in India is being viewed as a high growth Industry. Commercial floriculture is becoming important from the export angle. The liberalization of industrial and trade policies paved the way for development of export-oriented production of flowers. Flowers are not only grown for aesthetic purpose, but also have some nutritive and medicinal properties.

In many countries of the world edible flowers have been used in terms of nutritional value, medical effect, taste, shape, and aesthetic appearance (Mlcek J and Rop O., 2011) ${ }^{[13]}$. Edible flowers are flowers that are eaten. In most of the cases, stems, sepals, petals and stamens are removed before use (Newman SE, 2009) ${ }^{[10]}$. In general, edible flowers are eaten whole, but depending on the flower species, only some parts should be consumed. For example, only the petals of Tulipa, Chrysanthemum, Rosa spp. or the flower buds of daisies (Bellis perenis) or garden nasturtium (T. majus) are consumed. Furthermore, in some flowers it is necessary to remove some parts due to their bitterness such as the white portions of the roses and chrysanthemums petals base. They are preserved for future use by using techniques like drying, freezing or steeping in oil (Fernandes Luana et al., 2019) ${ }^{[4]}$.

The food habits have changing worldwide. Day by day people becoming health conscious and selective for nutritious food. Many researchers have revealed that these flowers play a vital role in human nutrition due to their richness of antioxidant, anti-carcinogen, vitamin, and many more chemical compositions (Rezende F et al., 2019) ${ }^{[12]}$. Another key success factor for the nurseries is to examine the inseparable factors of efficient input use, cost savings, enhanced product quality, and the sustainable nature of production or manufacturing practices. Nowadays, the heightened awareness of the critical trend in resource depletion and in environmental degradation impels us to constantly improve the eco - sustainability of any productive process (Falla NM, et al., 2020) ${ }^{[3]}$.

People are uses flowers in different cuisine as major or essential ingredients. Edible flowers are used both for adding sensorial properties (colour, taste, aroma, flavour), to decorate dishes (Prata et al., 2017) ${ }^{[11]}$. On social media era, people are demanding tasty food with more eyecatching appearance. Both the quality of foodstuffs and aesthetic aspects contribute to the appearance of consumed meals. The attraction and appeal of individual dishes could be enhanced by edible flowers.

The flower cultivation for edible purpose is neglected in floriculture industry, so it forms a new vision of flower cultivation and also become a source of revenue for floriculture industry with diversification. Many flowers are edible but proper identification is essential because some are poisonous (Acikgoz, 2017) ${ }^{[1]}$. Popular edible flowers include chrysanthemum, calendula, day lily, lilac, mint, marigold, nasturtium, pansy, rose, tulip and violet. 
Until now, there are no official lists of edible and non-edible flowers released by any authorized organization. In this context, the aim of this review was to determine potential of different edible flowers, aiming to strengthen the edible flower systematic cultivation on floriculture sector.

\section{Uses}

- Contributes significantly to meet nutritional requirement throughout the year (Sasi et al., 2011) ${ }^{[14]}$.

- Can be used as substitute of major food, especially in period of seasonal food shortage.

- As an ingredient in salads or garnish, entrees, drinks and desserts. Pansy, rose, nasturtiums, begonia, carnation and hibiscus are examples of edible flowers that are normally used to garnish dishes.

- Recipes with flowers have been applied to different food matrices namely, tea, baking, sauces, jelly, syrup, savoured liquors, vinegars, honey, and oils.

- Some flowers can be stuffed or used in stir-fried dishes.

- Uses as natural colorant, representing an alternative to the use of synthetic dyes in foods.

- They are usually used to add color, fragrance and flavor to food such as saladsor garnish, soups, entrees, desserts and drinks (Rop et al., 2012) ${ }^{[13]}$.

- The most frequent way to consume edible flowers is in fresh butthey can also be consumed dried, in cocktails (in ice cubes), canned in sugar and preserved in distillates (Mlcek and Rop O, 2011) ${ }^{[9]}$.

- Flower-flavoured oils and vinegars are made by steeping edible petals in these liquids. Sometimes candied flowers are crystallized using egg white and sugar (De L. C., 2020) ${ }^{[2]}$.

- Oils from flowers are used in aromatherapy, and certain flowers are even used as a dietary therapy due their medicinal value.

- Furthermore, flowers were used as decorations in food prepared for the nobility, especially for feasts and banquets (Rop O et al., 2011) ${ }^{[9]}$.

Traditionally many ornamental plants used as edible flowers like Antirrhinum majus, Centaurea cyanus, Chrysanthemum frutescens, Dianthus caryophyllus, Fuchsia $x$ hybrida, Impatiens walleriana, Rosa odorata, Tropaeolummajus, Viola $x$ wittrockiana, Begonia boliviensis, Chrysanthemum parthenium, Tagetespatula etc. but the systematic data was unavailable. Here the some important, easy growing ornaments characteristics can be grown as edible flower-

Cosmos: This is an annual plant, having 90-120cm tall and produce white, orange, red, pale yellow single or double type flowers. Flower heads are good yellow colorants. Flowers are edible and used in salads. Flowers have antioxidant and antiinflammatory activities.

Marigold: Both French marigolds (Tagetes spatula) and African marigolds (Tageteserecta) flowers are edible. Flowers of French marigold are yellow, orange and unique bronze in colour. In African marigold, flowers are yellow or orange in colour. In T. tenuifolia, flowers are yellow, orange, golden or bicoloured borne above the fine textured dark green foliage or tucked in with the foliage depending upon the cultivar. African marigold flowers are used as a food colourant in Europe, but have only been recommended for use as a poultry feed additives. However, T. tenuifolia has a refreshing citrus, lemony flavour, and its petals are used in salads or smart drinks. The flowers of Tagetes erecta is carminative, diuretic and vermifuge. Flowers are used in the treatment of fever, flu, sore throat, heart attack and arthritis.

Nasturtiums: The flower, leaves and seed of Nasturtiums are edible. The tangy flavor is mustard like, with an added perfume and sweetness. Harvest the flower just as open. Flowers come in deeply intense hues of cream, yellow, orange, and red, which are set off beautifully by the sea of green leaves. It is growing easily as climbing, cascading and busy in pot, bed and border. It contains Glucosinolates which has antibiotic and anti-tumour effects and good source of vitamin C, spilanthol and oxalic acid (Kumari P. and Adarsh M.N., 2016).

Pot Marigold: These are hardy herbs, attains a height of 30$60 \mathrm{~cm}$ and the flowers are generally orange -yellow. Leaves are large, simple and alternate. These free flowering plants bear double or semi-double flowers of brilliant colour, mostly orange, yellow or lemon. Calendula is valuable for sunny or shady beds or borders and also as cut flowers and pot plant. Flower petals are edible. They have nice flavor, bitter to peppery in taste and are sprinkled on soups, pasta or rice dishes, herb butters, and salads. Petals add a yellow tint to soups, spreads, and scrambled eggs. The dried flower heads have antipyretic, anti-tumor and cicatrizing effects. Topical application of infusion of flowers is used as antiviral in HIV (Kalvatchev et al, 1997) ${ }^{[6]}$, antifungal, and antiseptic in wounds, marks, freckles, sprain and conjunctivitis and improves immune systems.

Rose Rosa gallica: It is a deciduous shrub forming large patches. The slender, straight prickles are various in size in this species The leaves are pinnately-compound, with three to seven bluishgreen leaflets. The flowers are clustered one to four together, on glandular pedicels. Rose has a sweet and perfumed flavor. Remove the white, bitter base of the petal for consumption. Rose hips are rich in Vitamin - C, flavonoids and tannins (Sharma et al., 2011) ${ }^{[16]}$. In miniature varieties, garnishice cream and desserts, or larger petals can be sprinkled on desserts or salads. Freeze them in ice cubes and float them in punches also. Petals used in syrups, jellies, perfumed butters and sweet spreads. Other valuable products are rose petal jam, rose petal tea etc. The petals are antibacterial, astringent, anti-inflammatory, antifungal and antiviral for human health (Acikgoz, 2017, Shamspur and Mostafavi, 2009) ${ }^{[1,15]}$.

Harvesting of edible flowers: Flowers were harvested in full ripeness from five randomly chosen plants of each species (cultivar) (Hertle, B et al,1993) ${ }^{[8]}$. The degree of edible flower full ripeness was determined on the basis of flower size, opening and colouring Edible flowers should be harvested in the cool of the day during the peak of bloom because they are in their best flavour. Only flowers free of insect and disease problems should be selected. The collection of unopened blossoms (except daylilies) and wilted or faded flowers should be avoided because they may have a bitter or unappealing flavour (Newman and O'Connor, 2013) ${ }^{[10] .}$ Concerning flowers' parts, the stems, sepals, pistils and stamens of most flowers should be removed prior to use. Pollen may detract flower's flavour and may cause allergies in some people. The sepals should be removed from all 
flowers due to their sourness, except violas, pansies and Johnny jump-ups whose sepals are more tasteful. In many flowers (including rose, lavender, tulip, calendula, and chrysanthemum) only the petals are edible (Gupta Y. C.et al, 2018) ${ }^{[5]}$.

\section{Conclusion}

Globalization has contributed not only to a better awareness of consumers but also to the comeback of earlier lifestyles, in which edible flowers played an important role. Edible flowers have emerged as the latest food fashion in developed and developing countries, making this niche market very challenging. Also these Covid situations make flower industry to innovate new avenues. Producers and marketing agencies of edible flowers (supermarkets, local markets, online) are increasing around the world, whereas consumers and professional chefs are demanding higher quality products. These are the innovative ingredients of future foods for diversification.

\section{Reference}

1. Acikgoz. Edible Flowers. Journal of Experimental Agriculture International 2017;17(1):1-5. Article no.34564.

2. De LC. Popular Edible Flowers for Immunity Development of Individuals. Agriculture Observer 2020;1:2;4-9.

3. Falla NM, Simone C, Sonia D, Matteo C, Valentina S. Environmental Impact of Edible Flower Production: A Case Study. Agronomy 2020;10:579.

4. Fernandes Luana, Jorge A, Saraiva, José A Pereira, Susana Casal, Elsa Ramalhosa. Post-harvest technologies applied to edible flowers: A review. Food Reviews International 2019;35(2):132-154.

5. Gupta YC, Priyanka Sharma, Gitam Sharma, Roshini Agnihotri. Edible Flowers, National Conference on Floriculture for Rural and Urban Prosperity in the Scenario of Climate Change 2018;25-29.

6. Kalvatchev Z, Walder R, Garzaro D. Anti-HIV activity of extracts from Calendula officinalis flowers. Biomedical Pharmacology 1997;51:176-180.

7. Kumari P, Adarsh MN. Flowers: a new source of nutraceuticals and various approaches to increase nutraceutical compounds in flowers. Ecology, Environment and Conservation 2016;22(2):971-975.

8. Hertle B, Kiermeier P, Nickigov M. Gartenblumen. Gräfe and Unzer: München. Germany 1st Ed 1993, pp30-200.

9. Mlcek J, Rop O. Fresh edible flowers of ornamental plants a new source of nutraceutical foods. Trends in Food Science and Technology 2011;22:561-569.

10. Newman SE, O'Connor AS. Edible flowers. Colorado State University, Extension 2009;12/96, 7.237.

11. Prata GB, de Souza KO, Lopes MMA, Oliveira LS, Aragao FAS, Alves RE, et al. Nutritional characterization, bioactive compounds and antioxidant activity of Brazilian roses (Rosa spp). Journal of Agricultural Science and Technology 2017;19:929-941.

12. Rezende F, Sande D, Coelho AC, Oliveira G, Boaventura MA, Takahashi JA. Edible Flowers as Innovative Ingredients for Future Food Development: Antialzheimer, Antimicrobial, and Antioxidant Potential. Chemical Engineering Transactions 2019;75:337-342.

13. Rop O, Jiri Mlcek, Tunde Jurikova, Jarmila Neugebauerova, Jindriska Vabkova. Edible Flowers-A
New Promising Source of Mineral Elements in Human Nutrition. Molecules 2012;17:6672-6683.

14. Sasi R, Rajendran A and Maharajan M. Wild edible plant Diversity of Kotagiri Hills - a Part of Nilgiri Biosphere Reserve, Southern India. Journal of research in Biology 2011;2:80-87.

15. Shamspur T, Mostafavi A. Chemical Composition of the Volatile Oil of Rosa Kazanlik and Rosa gallica from Kerman Province in Iran. Journal of essential oil-bearing plants 2009;13(1):78-84.

16. Sharma Y, Hegde RV, Venugopal CK. Health and nutrition from ornamentals. International Journal of Research in Ayurveda and Pharmacy 2011;2(2):375-382. 